\title{
ENSINO E APRENDIZAGEM EM ESTUDOS DE USUÁRIOS: interlocuções nas práticas docentes
}

\author{
TEACHING AND LEARNING OF USER STUDIES: interlocutions teaching \\ practices
}

\author{
Maria de Fátima Oliveira Costa
}

UFC

\section{RESUMO}

Aborda acerca das interlocuções feitas por meio de práticas docentes sobre o ensino e aprendizagem. Traz algumas reflexões possíveis de despertar aspectos relacionados ao entendimento de práticas com Estudos de Usuários, no intuito de gerar discussões e contribuir para o ensino da disciplina de Estudo de Comunidade e de Usuários, focando pontos que possam interferir no relacionamento humano, despertando e orientando o conhecimento do aluno. Essa atenção dada ao objeto principal da Biblioteconomia e da Ciência da Informação, o Usuário, deve ser valorizada no trabalho do profissional e em especial, no aprendizado do aluno, e consequentemente, na sua futura atuação profissional. Procurou-se mostrar os aspectos teóricometodológicos, em que pesem o ensino e a pesquisa, levando à aprendizagem dos estudantes e à sua formação. A metodologia seguida foi a pesquisa bibliográfica, consultando bases de dados sobre a temática, a literatura sobre o tema e suas relações. Estimula à uma prática docente, que deve ser aprimorada de maneira permanente, por meio da educação continuada, no respeito as diretrizes curriculares traçadas na área. Além disso, sinaliza a promoção de práticas, a fim de debater questões inerentes a desafios postos ao mercado e aqueles que advirão no cotidiano do trabalho profissional.

Palavras-chave: Ensino e Aprendizagem. Ensino da Disciplina sobre Usuários. Estudos de Usuários. Práticas docentes.

\section{ABSTRACT}

It addresses the interlocutions made through teaching practices about teaching and learning. It brings some possible reflections to awaken aspects related to the understanding of practices with User Studies, in order to generate discussions and contribute to the teaching of the Community and Users Study discipline, focusing on points that may interfere in the human relationship, awakening and guiding the knowledge of the student. This attention to the main object of Library Science and Information Science, the User, should be valued in the work of the professional and especially in the student's learning, and consequently in his future professional performance. We tried to show the theoretical and methodological aspects, in which teaching and research weigh, leading to students' learning and their formation. The methodology followed was the bibliographical research, consulting databases on the theme, the literature on the subject and their relationships. It stimulates a teaching practice, which must be permanently improved, through continuing education, in compliance with the curricular guidelines outlined in the area. In addition, it signals the promotion of practices, in order to discuss issues inherent to challenges put to the market and those that will come in the daily work of professionals.

Keywords: Teaching and learning. Discipline teaching about users. User Studies. Teaching practices. 


\section{INTRODUÇão}

Por ocasião de sua realização, o I Encontro Internacional de Estudos de Uso e Usuários da Informação, nos fez pensar o ensino e aprendizagem por meio dessa temática. Pois, conversar, estudar e dialogar sobre usuários vem sendo um dos temas mais fascinantes dentro da área profissional, por se tratar de sujeito, de ator e de objeto em que há plena interatividade entre os mesmos; assim, assumimos ser este entendimento o passo mais próximo a oferecer respostas sociais.

Nesta oportunidade, a partir de eixos determinantes, que foram discutidos no referido evento e, entre eles, o de ensino e aprendizagem, já explicitado, cabendo-nos a responsabilidade de desenvolver pontos que considerássemos relevantes na formação profissional, dentro do ensino da disciplina de Estudos de Usuários, considerando também a motivação que deve ser mostrada aos alunos, além do estimulo à valorização que a função social exerce na atuação do profissional.

Quando falamos na função social, ela se torna condição sine qua non para que a atuação do profissional seja pró ativa, e, pois, tenha dinâmica diferenciada em utilizar estratégias que possam ir além do que o mercado está a exigir.

Há algo que nos preocupa, do lado profissional, quando teoricamente lembramos sempre do usuário, e dizemos que trabalhamos para ele; organizamos e processamos a informação e a disseminamos em função de possível recuperação, uso e assimilação da informação; porém, na prática, ainda é trabalhada de maneira inexpressiva, vez que serão mais relevantes a instituição, o profissional, o sistema se, não olhar, ainda, de maneira insignificante, leve ou fragilizada para o ser, usuário.

Além de tornar esse profissional, como mediador da informação, teremos que chamar a sua atenção para o significado que tudo isso terá, se a formação dele não estiver voltada para o atendimento pleno a seus respectivos usuários. Embora sejamos sabedores de que não temos garantia que nos certifique que a informação cheque com significado para ele, o usuário pois tal atitude é imprescindível.

Esses pontos merecem uma cuidadosa atenção dos pesquisadores, docentes e profissionais em podermos identificar e conhecer o comportamento de busca e as necessidades de informação dos usuários em prol do desenvolvimento de ações que o sistema de informações deva cobrir.

Assim sendo, buscamos elaborar este trabalho para que dê suporte a prática profissional em que o usuário seja de fato aquele principal gerador de motivação da 
atuação do profissional da informação, isto é, o protagonista do trabalho do bibliotecário e de outros profissionais da informação.

Há uma variedade de trabalhos publicados na área de usuários no Brasil; a prática e vivência de pesquisa com usuários, todavia, ainda está muito aquém do ideal; apesar de termos volume considerável de publicação internacional nesta área, embora careça de práticas que possam fortalecer tal olhar e vivência para o usuário.

$\mathrm{Na}$ Ciência da Informação é perceptível ainda a insuficiência de estudos resultantes das publicações, quer sejam em nível de pós-graduação ou mesmo nos trabalhos de conclusão dos cursos de Biblioteconomia, quanto à temática sobre usuários da informação, embora exista pesquisa com usuários, a temática surge apenas como nuance, ao invés de ser tornada como essência.

Assim, queremos chamar a atenção do leitor, pesquisador, docente, profissional, no escopo de perceber e, pois, entender, completamente, que o fim, enquanto resultado, nas áreas de informação, continuará sendo o usuário, na perspectiva de ser tratado como sujeito, autor de sua ação, como o motivo principal da área da Ciência da Informação.

Assim, concebemos que é a partir do ensino da disciplina de estudos de usuários, que deveremos incentivar nossos alunos em sala de aula, explicitando que os ambientes informacionais são diversos, com vasta complexidade e que se utilizam fontes e formatos dos mais diferentes, tornando evidente a percepção de que o usuário se constitui ator principal no trabalho do profissional bibliotecário.

Por esta razão, quando pensamos no ensino da disciplina referenciada, devemos fazer jus a que haja as interlocuções entre o professor e, evidentemente, o aluno, em função de alertar, referir e debater acerca do assunto em pauta.

Desse modo, estimulamos o aluno a que valorize e se identifique com o trabalho social, compreendendo, afinal, ser o serviço fim da profissão levar sempre e facilitar a informação, e que tenha verdadeiro significado para a sociedade.

O bibliotecário, por exemplo, entre outros profissionais da informação, deverá ir além de seu entusiasmo nesse papel de disseminar e respeitar a profissão por esse lado mais nobre que é o de compreender, servir, interagir e satisfazer as demandas da sociedade, com novos termos, novos conceitos, novos métodos e novos saberes.

Em relação aos novos saberes, Antunes (2009, p 73) explicita: 


\begin{abstract}
Não importa qual disciplina, menos ainda qual o tema, é sempre papel irrecusável de todo professor buscar nos conhecimentos do aluno os "ganchos" para fundir os saberes que se desenvolvem. Nunca o novo que ensinamos é guardado na memória, se não o ativarmos com um saber antigo e pessoal lá existente.
\end{abstract}

Então debatemos a questão de como levar tais reflexões ao ensino da disciplina que trata de pesquisa com usuários da informação.

Com essa instigação, devemos inicialmente conhecer a Lei de Diretrizes e Bases, reformulada, recentemente, neste ano de 2017, além do conhecimento das Diretrizes curriculares aprovadas em versão preliminar em 1998 e, posteriormente em 2001, pelo Ministério da Educação - MEC, e outras propostas curriculares dos cursos de Biblioteconomia, Arquivologia e Museologia, dentre os demais documentos que tratam acerca de usuários da informação.

Tais instrumentos servem de base à construção de propostas pedagógicas e se tornam desafios à formação do professor universitário, no propósito de provocar as interlocuções no ensino superior, tão exigidas para o possível sucesso do formando.

\title{
2 PENSAR O ENSINO E APRENDIZAGEM DOS ESTUDANTES E A PRÁTICA DOCENTE
}

No planejamento de disciplinas referentes àquelas que formam o profissional da informação, em se tratando de bibliotecas, arquivos, e ambientes afins, o bibliotecário ou outro profissional, deverá ter um olhar mais real para os usuários da informação e requerer que haja não só conhecimento dessa temática, mas, domínio do que deve ser tratado acerca do tema e de sua legislação.

No caso da Lei de Diretrizes e Bases (LDB), abrangente nos mais diferentes tipos de educação, e que rege os princípios gerais da educação, desde 1996, com última atualização em março de 2017 e, portanto, a educação superior, também; a qual deve ser seguida pelas instituições de Ensino Superior, ou seja, as universidades, temos que abrir o debate.

Na época de sua edição, funcionavam os currículos mínimos, e isto dificultava sua implantação, devido a inserção de diversas disciplinas que complementassem os currículos; o que, aliás, hoje, já não se constitui motivo para a manutenção da rigidez nos currículos. As diretrizes curriculares, que foram as bases para a geração das propostas 
pedagógicas dos cursos de graduação, facilitaram, de certa forma, superar tal rigidez outrora existente.

Assim, atualmente pode-se ter maior liberdade em desdobrar as temáticas, surgidas pelas próprias exigências do mercado ou além dele, gerando disciplinas que pudessem formar uma harmonização curricular integrada, em prol do avanço exigido pela própria sociedade.

Desse modo, foram pensados os projetos pedagógicos de cursos superiores com o apoio da Associação Brasileira de Educação em Ciência da Informação (ABECIN), além de eventos, em diferentes níveis, os quais geraram debates sobre disciplinas com suas respectivas ementas, objetivos, metodologias no fito de serem gerados os planos de ensino de cada uma delas.

Dessa forma, foram elaborados os programas dessas disciplinas e, entre elas, a de Estudos de Usuários, com o intuito de melhor motivar ao alunato o rendimento acadêmico. Cumprir tal medida deverá ter o permanente incentivo ao crescimento espontâneo de cada aluno.

Em sala de aula, pressupõe-se que haja perfeita ou quase perfeita interatividade entre docente e discente, em busca de aprendizagem. Segundo algumas pesquisas divulgadas, faz-se necessário vislumbrar o que diz os seguintes autores, acerca da aprendizagem:

\begin{abstract}
A aprendizagem é então um processo ativo no qual os alunos constroem o seu próprio conhecimento interagindo com o conteúdo temático, transformando-o e discutindo-o com os colegas, professores, público, a fim de internalizar o significado e fazer conexões com o conhecimento existente. Neste processo, há evidências consideráveis de que o feedback tem uma influência inquestionável que levam a uma melhor compreensão e a resultados de aprendizagem efetivos. (BORRALHO; FIALHO; CID, 2009, p. 989).
\end{abstract}

Por esta razão, o docente terá que se utilizar das mais diferentes e atuais fontes e formas de como levar um ensino de qualidade, com conteúdos práticos, reflexivos e que possam contribuir para a vida pessoal e profissional a partir da possibilidade de gerar novos conhecimentos, motivando aos estudantes à discussão, a criatividade e, assim, poder estimulá-los a gostar da disciplina, a participar de ações e práticas que se tornem estimulantes e que possam ser úteis à vida.

Dentre as práticas do ensino com a pesquisa, por exemplo, lembramos o que diz Freire (1996, p 29) em sua obra Pedagogia da Autonomia, interagindo ensino e pesquisa, 
ao afirmar: "Ensino porque busco, porque indaguei, porque indago e me indago. Pesquiso para constatar, constatando, intervenho, intervindo educo e me educo. Pesquiso para conhecer o que ainda não conheço e comunicar ou anunciar a novidade."

Assim, percebemos que o estímulo a pesquisa deve ser uma constante na vida acadêmica, se iniciando pelo próprio docente, seguindo aos estudantes na graduação e na pós-graduação. Em sala de aula é que deve ser provocada tal prática.

Nesta disciplina, ora em estudo, a pesquisa realizada pelos estudantes com usuários deve ser estimulada e praticada como resposta ao seu aprendizado, até porque "[...] o comportamento do usuário da informação se dá com a apropriação da informação no processo de assimilação, que se acentua principalmente por meio da pesquisa. " (COSTA, 2016, p. 123).

Como será possível adotar essa tal prática? A indagação é válida quando se coloca conteúdos que possam despertar interesse que levem a se tornarem curiosos, de modo a que possam enfrentar desafios para sua vitória na aprendizagem. Sabemos que não é uma tarefa fácil, e sim desafiadora, por entendermos a conjuntura vivida que nem sempre favorece ao sonho e à crença nesses valores, ora explicitados.

Uma lembrança que vem à mente é a de que devemos sempre apresentar conteúdos que façam o estudante se reinventar, e examinar suas aptidões, as suas vontades de descobertas, no enfrentamento de dificuldades, em assertivas e, nunca, na descrença; além de mobilizar o alunato em busca de competências favoráveis ao enfrentamento das dificuldades. E para desenvolvê-las faz-se necessária a busca de saberes e habilidades para a construção e o desenvolvimento da cidadania.

A cidadania deve ser um ponto a ser trabalhado no início da disciplina; o que deverá acontecer a partir da participação que o indivíduo tem na sociedade, como também, sua prática no cotidiano perante si próprio e diante do coletivo. Assim, os tornaremos capazes de atuar como cidadãos de fato e de direito.

A metodologia utilizada pelo docente também influenciará no percurso da formação do educando. Entendendo dessa forma, com certeza, o ensino deve ser focado na aprendizagem do aluno. Vejamos:

Um modelo centrado na aprendizagem vai focar-se mais nas competências e saberes que os alunos vão adquirindo ao longo do seu processo de formação. Este processo pressupõe metodologias de ensino que não se limitem à mera exposição de conteúdos, mas que passem a valorizar formas de aprendizagem onde o aluno seja chamado a participar, a debater, a colocar em uso o 
conhecimento em situações e problemas concretos. A avaliação daqui decorrente terá então de ser mais abrangente e diversificada para dar resposta à complexidade e subjetividade. (BORRALHO; FIALHO, 2009, p. 989).

Assim, o discurso do professor deve sempre lembrar que o profissional da informação deve estar atento ao caráter ativo dos usuários, não só a habilidade individual, mas a sua socialização. Entendendo assim, torna-se possível a conquista de seus direitos enquanto cidadão.

0 professor deve estar atento a uma criticidade de seu fazer, lembramos Freire (1996, p. 39):

Por isso é que, na formação permanente dos professores, o momento fundamental é o da reflexão crítica sobre a prática. É pensando criticamente a prática de hoje ou de ontem que se pode melhorar a próxima prática. 0 próprio discurso teórico, necessário à reflexão crítica tem de ser de tal modo concreto que quase se confunda com a prática.

A educação se concretiza quando humaniza o homem, e acontece por meio do ensino que possibilita a geração do conhecimento e a liberdade de pensar. E continuando o que diz Freire (1997, p. 43), se considerarmos que:

[...] ensinar não é transferir conhecimento, mas sim criar possibilidade para sua construção e sua produção. Quando você ensina, você forma e se forma; quem ensina aprende ao ensinar e quem aprende ensina ao aprender. Ensinar exige segurança, competência profissional e generosidade. Ensinar é uma especificidade humana.

Ensinar e aprender se inter-relacionam de maneira compartilhada. É uma construção coletiva de soma, daí, surge a aprendizagem. Assim, o ensino aprendizagem se efetiva quando há o aprendizado mútuo, entre professor e aluno. Daí acontece as múltiplas possibilidades de melhoria na qualidade de vida, que elevam o ser humano cada vez mais e melhor, e esta melhoria se estende a toda a sociedade. (COSTA, 2016).

Dessa maneira, percebemos o compromisso e a complexidade do ensino. Lembremos Pimenta (2010, p. 17):

O ensino é uma prática social complexa. Realizado por seres humanos entre seres humanos, o ensino é transformado pela ação e relação entre os sujeitos (professores e estudantes) situados em contextos diversos: institucionais, culturais, espaciais, temporais, sociais. 
O ensino exige pesquisa, dedicação e um conjunto de ações no compartilhamento de ideias, e fazer com que haja sempre uma intermediação dialogada entre docente e discente no intuito de se utilizar as novas abordagens, a fim de atender as diferentes demandas e necessidades de informação de cada usuário permanentemente e não apenas ocasional.

\section{MOTIVAÇÃO AO USUÁRIO, ORIUNDA DE DIFERENTES AMBIENTES INFORMACIONAIS}

Quando se fala em usuário, ficamos a imaginar como este se planeja para visitar, consultar e ou buscar e ter acesso a informação, com os diferentes sistemas de buscas de forma física ou virtual, embora o acesso que ele queira ter independa ou não do suporte e formato em que se encontra a informação.

Podemos citar os ambientes das bibliotecas, dos arquivos, dos museus com suas diferentes funções, e as diversas unidades e centros especializados de informação, os quais, por sua vez, poderão ter diferentes propósitos. Lembramos, assim, Moreiro González, (2005, p. 177) quando expressa que "El objetivo es que los usuários no se pierdan en la gigantesca cantidad de documentos existentes, y puedem aceder de forma rápida y pertinente a la información que desean.” A linguagem documentária deve estar clara e coerente aos seus usuários.

Cada ambiente deve ter sua função informativa. As bibliotecas, por exemplo, devem atender e desenvolver as funções de difusão da informação, procurando disseminar informações que o usuário necessite. Juntamente com as funções práticas que permitem a esses usuários a obtenção de respostas, além das demais funções formadoras, no apoio a educação, de custódia, recreativas, social e de investigação. (MOREIRO GONZALÉZ, 2005, p. 75-76).

Ainda tratando de ambientes informacionais, podemos citar, também, os ambientes dos museus que segundo o referido autor, acima citado, é um centro que coleciona e conserva objetos sempre relacionados ao seu contexto histórico, natural e social.

Considera ainda que "El museo, es por tanto, un sistema de información cuyo material informativo no son documentos, ni datos, sino objetos." (SHERA, 1980, apud MOREIRO GONZALEZ, 2005, p. 103). 
Ainda no tocante aos museus, Moreiro Gonzalez considera um lugar de exposição, de trabalho e de investigação que se constitui como propriedade cultural no sentido de apoiar as pesquisas científicas, atuar como escola difusora que utiliza os meios informativos existentes para educar os visitantes e servir de depósitos de peças de interesse. Afirma que "Archivos, bibliotecas y museus han sido tradicionalmente los lugares depositarios de los resultados más valiosos del trabalho cientifico. " (MOREIRO GONZALEZ, 2005, p. 104).

Daí imaginar que o bibliotecário ou outro profissional que trabalhe com a informação no contexto da ciência da informação, esteja atento às mais diferentes situações de que cada usuário transforma a informação a depender de seus conhecimentos, de seus sentidos.

Desde a década de 1980, conhecemos trabalhos de resultados de pesquisa de dissertação de mestrado que já sinalizavam, não com o envolvimento ainda dessas áreas, mas com o teor crítico que favorecessem ao pensamento que ora expressamos.

Convém levarmos aos estudantes o pensamento de que o profissional deve compreender o sentido da busca e do uso da informação por seus usuários, com o significado esperado.

Assim, tal situação, ainda está distante do que se almeja. Ainda no modelo vigente de Wilson (1981, 1996, 1997), o autor tenta aperfeiçoar o primeiro modelo de comportamento informacional, explicitando que toda situação problema deve ter o espaço de tempo para a devida solução do referido problema. E ainda ressalta que não significa que o usuário obtenha êxito; ou seja, ele poderá ter sucesso ou não na busca efetivada, o que não invalida a busca como tal.

\section{DESAFIOS À ATUAÇÃo PROFISSIONAL COM OLHAR NO USUÁRIO}

Acreditamos que a relação entre docente e discente seja por demais confiável, por isso há urgência em chamar a atenção dos estudantes e despertar na sua aprendizagem, mais crítica e reflexão e que por meio da disciplina de Estudos de Usuários da Informação, os estudantes se sintam mais motivados para a responsabilidade e o compromisso, juntamente com a vontade técnica e política.

Ultimamente, percebemos certo descaso ou talvez determinada displicência ou falta de interesse e motivação, quanto ao papel que o bibliotecário possa e deva assumir 
no mercado de trabalho, no que respeita ao que é exigido dele; no mínimo, o domínio do conhecimento da temática sobre os usuários, o que se percebe; a falha na cognição em procurar ter uma visão hermenêutica, ao invés de uma visão excessivamente e apenas técnica, sem olhar para o usuário.

Temos que mostrar aos nossos alunos o comportamento e visão ética para atuação mais primorosa, na qual o docente sirva de bússola não só numa prática isolada, mas na avaliação permanente. Supondo que as universidades não deixem os docentes com inteira liberdade ou independência na formação do docente, Nóvoa (2002, p. 23) afirma: “[...] o aprender contínuo é essencial e se concentra em dois pilares: a própria pessoa, como agente; e a escola, como lugar de crescimento profissional permanente".

Assim, a formação profissional se torna mais aprimorada, por meio de reflexões e debates promovidos pelas pesquisas desenvolvidas mediante grupos e projetos.

Entre as atividades do docente, a elaboração do plano de ensino torna-se condição inicial para estabelecer as propostas do ensino da disciplina. Evidentemente sempre de conformidade com a instituição de ensino superior, pois "De fato, os planos deveriam cumprir o papel de diretriz para o professor seguir e o aluno acompanhar, como uma espécie de manual, que ajuda aos dois no planejamento e execução do ensino e aprendizagem". (COSTA, 2016, p. 131).

Conforme o pensamento de Nascimento (2010), sinaliza alguns aspectos e que foram resultantes de pesquisa feita sobre os planos de ensino da disciplina de Usuários da Informação, no período de 2007 a 2009:

\footnotetext{
Ao buscar novas informações para se atualizar, o docente se coloca na posição de usuário da informação; ao transmitir conhecimento em sua prática pedagógica é, ao mesmo tempo, consumidor e divulgador da informação, ao passo que enquanto pesquisa produz conhecimento, gera novas informações e enriquece a bibliografia do plano de ensino com literatura pertinente e atualizada (NASCIMENTO, 2010, p. 2).
}

Nessa perspectiva, observamos que o docente assume papel relevante na organização de toda a trajetória da formação do educando.

Em se tratando da disciplina de Estudos de Usuários, devemos lembrar que as abordagens tratadas na referida disciplina devem ser trabalhadas de conformidade com o paradigma social definido por Capurro. 
O professor não deve esquecer que será sempre um orientador de leituras, e motivador de descobertas de necessidades de informação, além de incentivar os temas de pesquisa que sejam sempre do interesse dos alunos.

\section{REFLEXÕES FINAIS}

Em se tratando de uma temática ligada ao eixo de ensino e aprendizagem em Estudos de Usuários da Informação, sinalizando para a disciplina referenciada, isto é, de estudos de usuários, motivo da temática do evento, esperamos que os docentes dessa área, com o encanto e domínio que devem ter, possam mostrar aos alunos dos cursos de graduação e de pós-graduação toda a garra e entusiasmo em elevar o conhecimento, em busca de novos saberes e novos olhares para o usuário da informação.

Temos que focar a crítica no ensino da disciplina sobre usuários, a partir do comportamento docente, na sua prática pedagógica, o que devemos ter e ser, e o comportamento que deveríamos ter em prol de um ensino que possibilite gerar a aprendizagem construtiva para o exercício que é de suma importância: tornar nossos alunos críticos e reflexivos, a ponto de estimulá-los cada vez mais no pensamento altruísta acerca de usuários.

Desse modo, podermos fazer as devidas interlocuções almejadas, colocando o docente numa posição de parceiro e, ao mesmo tempo, líder, com autoridade de domínio e habilidade no ato de interagir com a turma, de ensinar e favorecer à elevada formação profissional atuando na área da informação com zelo no principal personagem - o usuário como protagonista social.

No ensino da disciplina de estudos de usuários, devem ser preservados os aspectos da qualidade e da adequação teórica conceitual, de conteúdos e metodologias, sendo respeitadas as diretrizes curriculares e a legislação vigente na instituição de ensino superior.

O docente aqui entendido como aquele que, além de dominar conhecimento, seja capaz de exercer uma prática social que possibilite ao alunato a pensar, a criar e a gostar de servir a sociedade. Com efeito, este é o propósito que nos deve motivar.

\section{REFERÊNCIAS}


ANTUNES, Celso. A prática de novos saberes. 2. ed. Fortaleza: Ed. IMEPH, 2009.

BORRALHO, António; FIALHO, Isabel. CID, Marília. Aprendizagem no ensino superior: relações com a prática docente. In: Carlinda Leite; Miguel Zabalza. (Org.). Ensino superior: inovação e qualidade na docência. Porto: Centro de Investigação e Intervenção Educativas, 2012, p. 984-996. Diponível em: < https://dspace.uevora.pt/rdpc/bitstream/10174/7015/1/Aprendizagem\%20no\%20en sino\%20superior\%20Rela\%C3\%A7\%C3\%B5es\%20com\%20a\%20pr\%C3\%A1tica\%20d ocente\%2C\%20pp.\%20984-996.pdf>. Acesso em: 10 abr. 2017.

COSTA, Maia de Fátima Oliveira. Estudos de usuários da informação: ensino e aprendizagem no Brasil. Fortaleza: Edições UFC, 2016.

FREIRE, Paulo. Pedagogia da autonomia: saberes necessários à prática educativa. 25 . ed. São Paulo: Paz e Terra, 1996.

Pedagogia da autonomia: saberes necessários à prática educativa. São Paulo: Paz e Terra, 1997.

MOREIRO GONZÁLEZ, José Antonio. Conceptos introductorios al estudio de la información documental. Salvador: EDUFBA/Fondo Editorial de la Pontificia Universidad Católica del Perú, 2005.

NASCIMENTO. Maria de Jesus. Planos de ensino de "Usuário da Informação" nos cursos de biblioteconomia do brasil. DataGramaZero - Revista de Ciência da Informação, v.10, n.1, fev. 2010. Disponível em:

<www.dgz.org.br/fev.2010/Art_01.htm>. Acesso em: 10 maio 2017.

NÓVOA, António. Formação de professores e trabalho pedagógico. Lisboa: Educa, 2002.

PIMENTA, Selma G. Epistemologia da prática ressignificando a didática. In: FRANCO, Maria Amélia S.; PIMENTA, Selma G. (Org.). Didática: embates contemporâneos. São Paulo: Ed. Loyola, 2010. p. 15-42.

WILSON, Thomas D. On user studies and information needs. Journal of Documentation, v. 37 n. 1 , p. $3-15,1981$.

; WALSH, C. Information behaviour: an inter-disciplinary perspective. British

Library Research and Innovation Report, n. 10, 1996.

Information behaviour: an interdisciplinary perspective. Information

Proceeding and Management, v. 33, n. 4, p. 551-572, 1997. 
84 | Costa | Ensino e aprendizagem em estudos de usuários

\section{SOBRE OS AUTORES}

\section{Maria de Fátima Oliveira Costa}

Doutora em Ciência da Informação pela Universidade Estadual Paulista (UNESP).

E-mail: fatima12oliveiracosta@gmail.com

Recebido em: 13/03/2017; Revisado em: 10/04/2017; Aceito em: 15/05/2017.

\section{Como citar este artigo}

COSTA, Maria de Fátima Oliveira. Ensino e aprendizagem em estudos de usuários: interlocuções nas práticas docentes. Informação em Pauta, Fortaleza, v. 2, número especial, p. 72-84, out. 2017. 